\title{
Critical periods in language acquisition and language attrition
}

\author{
Christophe Pallier \\ Unité de Neuroimagerie Cognitive, INSERM U562, SHFJ \& IFR 49, \\ Orsay, France
}

\begin{abstract}
This paper reviews some of the predictions and assumptions made by different versions of the Critical Period Hypothesis which assumes that language acquisition will in principle be more successful in younger subjects. Findings from investigations of early vs. delayed acquisition of both a first and a second language which support this claim are presented. The question is then addressed whether the overall difference in ultimate attainment is a consequence of a loss of neural plasticity, or of the stabilizing of neural connections through the language learning process itself. The findings from a study of the $\mathrm{L} 1$ attrition of Korean adoptees in France are presented in support of the latter explanation.
\end{abstract}

Keywords: critical period; adoptees; neuroimaging; Korean

The issue of the "critical period hypothesis for language acquisition" is the focus of a vast literature (see, among others, Birdsong 1999a; Doupe \& Kuhl 1999; Harley \& Wang 1997; Lenneberg 1967; Long 1990; Newport, Bavelier \& Neville 2001; Singleton \& Lengyel 1995). It is important to stress at the outset that the expression "Critical Period Hypothesis" (CPH) is used with two different meanings. The first meaning of the $\mathrm{CPH}$ corresponds to an empirical hypothesis according to which humans are more efficient at language learning in the first years of life. In other words, the $\mathrm{CPH}$ states that age of acquisition is an important predictor of ultimate proficiency: the older one starts to learn a language, the smaller the odds of reaching native-like proficiency.

The expression "critical period hypothesis" is also sometimes used to refer to the concept that an age-related decline in neural plasticity is the cause of increasing difficulties in language learning (Penfield \& Roberts 1959). According to this second meaning, the $\mathrm{CPH}$ is a potential explanation of age effects on language acquisition. The two meanings must be distinguished because there may 
be a critical period according to the first meaning, that is, a detrimental effect of age of acquisition on ultimate proficiency in a language, even if the explanation in terms of loss of neural plasticity is wrong. In other words, an adverse effect of age of acquisition ( $\mathrm{AOA}$ ) may have other causes than irreversible neural changes (Birdsong 1999b lists some alternative explanations).

Another point is worth emphasizing. In the framework of the Critical Period Hypothesis (with the second meaning), it is often assumed that the putative loss of plasticity is due to maturational factors. Yet, it could also be the outcome of language acquisition itself, as suggested by the following quote from Wilder Penfield, one of the earliest advocates of the $\mathrm{CPH}$ :

Before the child begins to speak and to perceive, the uncommitted cortex is a blank slate on which nothing has been written. In the ensuing years much is written, and the writing is normally never erased. After the age of ten or twelve, the general functional connexions have been established and fixed for the speech cortex.

(Penfield 1965: 792, cited by Dechert 1995)

Another variant is defended by Steve Pinker:

Language acquisition circuitry is not needed once it has been used. It should be dismantled if keeping it around incurs any cost [...] Greedy neural tissue lying around beyond its point of usefulness is a good candidate for the recycling bin.

(Pinker 1994: 294-295)

The common theme is that once the child has learned the language(s) spoken around him, the neural modifications are irreversible. Before assessing the merits of competing theories, it has to be considered what the empirical evidence for a critical period with the first meaning is. Can language be acquired at any age or are the first years of life indeed critical?

Studies of critical periods in animals involve depriving the animals from some relevant stimulation during a given time window. For obvious reasons, this experimental approach cannot be used with humans: it would not be ethically acceptable to deny children exposure to language. Nevertheless, a few observations of abandoned children suggest that their language skills remained severely limited even after language instruction (e.g. Curtiss 1977; Itard 1964). Another source of information comes from studies of groups of congenitally deaf people who learned sign language as an L1 at different ages (Mayberry \& Eichen 1991; Newport 1990). These studies show that those who were exposed to sign language in their very first years of life control it better than those who learned it in midchildhood; the latter, in turn, perform better than those who were first exposed to sign language in their teens or later.

While it is sometimes proposed that neural changes critical for language acquisition occur around puberty, it seems that they can take place much earlier. Studies of auditory and language development in deaf children who receive cochlear implants - an auditory prosthesis that stimulates the auditory nerve in order to transmit acoustic information to the central auditory system - reveal that beneficial effects of earlier implementation can be observed in children when they are as young as 1 to 3 years of age (McConkey Robbins, Burton Koch, Osberger, Zimmerman-Philips \& Kishon-Rabin 2004; Tomblin, Barker, Spencer, Zhang \& Gantz 2005).

Are endogenous maturational factors the only cause of the age effect on L1 acquisition? There is evidence against this hypothesis. The fact that the deaf children who did not learn L1 in infancy were deprived from normal linguistic input in their first years of life plays a major role. This has been clearly established by Mayberry, Lock \& Kazmi (2001) who compared two groups of deaf adults who had learned American Sign Language (ASL) relatively late, between 9 and 15 years of age. ASL was the $\mathrm{L} 1$ for the participants of the first group, who were congenitally deaf. Participants in the second group were born with normal hearing and had started to acquire English before they became deaf. Therefore, ASL was their L2 (note that the grammar of ASL differs markedly from English grammar (Klima \& Bellugi 1979)). Mayberry et al. found that the second group largely outperformed the first in ASL. This result shows that experience plays a role because if only maturational factors were at play then the proficiency in ASL should only depend on age of acquisition of ASL and both groups should perform similarly. Moreover, the fact that those who learned an L1 early in life performed better than those who were deprived from any input contradicts Penfield's idea that exposure to the L1 "fixes" neural connections. On the contrary, learning and using a language in the first years of life maintains the capacity to acquire a new language. This observation corroborates the "exercise hypothesis" according to which the language learning capacity decreases when it is not used (Bever 1981).

The studies on the effect of age on the acquisition of an L1 demonstrate that deprivation has rapid detrimental effects on the capacity to learn a language. As deprivation is the usual test applied to assess critical periods in animals, it appears undeniable that there is a critical period for $\mathrm{L} 1$ acquisition in humans. The brain must be exposed to language to develop 'normally'. One possible explanation is that in the absence of linguistic stimulation, the brain areas that normally subserve language processing may be recruited for other functions. This interpretation is supported by data from Lee, Lee, Oh, Kim, Kim, Chung, Lee \& Kim (2001) showing that the benefits of cochlear implantation are inversely related to the amount of metabolism in the temporal lobes. In other words, deaf people who have an abnormally low metabolism in the temporal region profit more from 
Do delays in age of acquisition have similar effects for L1 and L2 acquisition? This is an important question because the answer could indicate whether the same mechanism is at work in both cases. To my knowledge, data on the effect of age on $\mathrm{Ll}$ acquisition are too scarce to know the precise shape of the age effect. Yet, the study by Mayberry et al. (2001) suggests that the effect of delay on L1 acquisition is much greater than for $\mathrm{L} 2$ acquisition. That is, the effect of deprivation on language learning seems much more devastating than the effect of having been exposed to an L1. Therefore, I believe it is likely that the effect of age of acquisition for an $\mathrm{L} 2$ is due to a different mechanism.

One possible explanation appeals to maturational factors that engender a progressive "loss of neural plasticity" in the brain (whether or not such a phenomenon would be specific to language networks is debatable). Another type of explanation postulates that it is the process of learning the L1 itself that stabilises neural connections. The more advanced the learning of the L1, the less the language networks can be modified by exposure to L2. Note that the two hypotheses are not incompatible: both mechanisms could be at play during development. For example, the proactive interference mechanism could be responsible for the slope of the age function observed in the first ten years of life, while the maturational constraints could play a role in the older age range.

As an instance of interference of L1 on L2 acquisition, consider the SpanishCatalan bilinguals described in Pallier, Bosch \& Sebastian-Gallés (1997). Despite extensive exposure to Catalan from the age of 4 to 6 , the native Spanish speakers do not perform like Catalan native speakers on the phonemic contrast between open versus close /e/. A likely explanation is that this phonemic contrast involves speech sounds which are assimilated onto a single phonemic category in Spanish (this situation is called single category assimilation by Best (1995) or perceptual equivalence by Flege, Takagi \& Mann 1995). Thus, speakers of Spanish as an L1 hear Catalan through the filter of the Spanish phonetic system, an example of interference from $\mathrm{L} 1$ onto $\mathrm{L} 2 .^{2}$

Disentangling maturational and interference accounts is not an easy task. Yet, it seems to us that while the maturational hypothesis entails the irreversibility of changes, interference theories need not make this prediction. That is, contrary to Penfield's assertion, the modifications engendered by the learning processes

2. In the title of the paper (Pallier, Bosch \& Sebastian-Gallés 1997) we used the expression "lack of behavioral plasticity" to describe this failure to acquire a new phonemic contrast. This is because we deemed it unlikely that this limitation was due to a lack of neural plasticity in the auditory cortex of the Spanish children. In the conclusion of the paper, we questioned whether such an effect was irreversible or not.

could be reversible. This leads to the interesting prediction that the acquisition of an $\mathrm{L} 2$ might be facilitated if $\mathrm{L} 1$ ceased to be used.

What happens when someone learns an L2 after having stopped using L1? International adoption provides an opportunity to address this question. A few years ago we contacted organisations in charge of adoption in France and recruited a small sample of young adults who had been adopted by French-speaking families in their childhood. They were all born in Korea and came to France when they were between 3 and 10 years old. All of them claim to have completely forgotten Korean (though some had memories from their life in Korea.) This is seemingly a very general phenomenon among internationally adopted children (Maury 1995, 1999). French had become the main language of our group of adoptees and they speak it fluently without any detectable accent. We will briefly review here some of the experiments performed on those participants (for more details, see Pallier, Dehaene, Poline, LeBihan, Argenti, Dupoux \& Mehler 2003; Sangrigoli, Pallier, Argenti, Ventureyra \& de Schonen 2005; Ventureyra 2005; Ventureyra \& Pallier 2004; Ventureyra, Pallier \& Yoo 2004).

Our first three behavioural experiments were designed to assess the adoptees' residual knowledge of the Korean language. Their performances were compared with that of a control group of native-French speakers who had never been exposed to Korean, nor to any other Asian language (Pallier et al. 2003). The Korean sentence identification experiment involved recognising sentences in Korean among recordings in different languages. In the word recognition experiment, participants heard two Korean words and had to select the one which was the translation of a given French word. Lastly, in the speech segment detection experiment, the task was to decide if specific speech fragments were present in sentences in various languages, including Korean. The results show similar patterns of performance for the adoptees and for the control group of native French speakers (see Figure 3), providing a first validation of the adoptees' claim that they had forgotten their Ll.

While the participants performed the speech segment detection task, their brain activity was monitored using functional magnetic resonance imaging (fMRI), a technique that allows to detect changes in patterns of brain activity when the participants process the stimuli. The individual analyses of fMRI data showed no detectable difference in brain activity when comparing the cerebral responses to Korean sentences versus Japanese or Polish sentences, two languages to which the adoptees had never been exposed. Thus, brain imaging data and behavioural data converge on the conclusion that years of exposure to a language in childhood are not sufficient to maintain a solid knowledge of this language.

This result can be interpreted in two different ways. First, the Korean language may have been "erased" from the brain of the adoptees. This would con- 


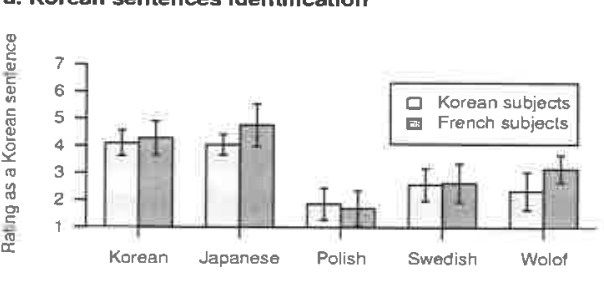

Stimuli

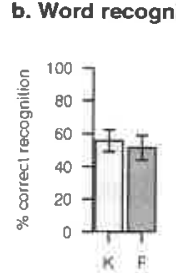

Group c. Speech segment delection

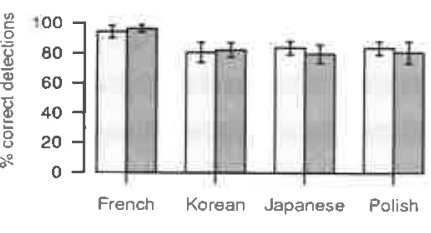

Stimu
Figure 3. Results on three behavioural tasks showing similar levels of performance of Korean adoptees and a control group of French native speakers

stitute strong evidence against versions of the $\mathrm{CPH}$ that state that some "neural connections" become fixed in the early years of life, as a result of learning and/ or because of maturational factors. Such theories predict that the adoptees (at least those who arrived at older ages) should have displayed some sensitivity to Korean. The metaphor of the imprinted clay tablet used by Penfield therefore has to be rejected. It must be noted, however, that as the adoptees from our studies arrived in France before the age of ten, we cannot exclude the possibility that irreversible changes occur after 10 years of age. ${ }^{3}$

A second possible interpretation is that the paradigms used by Pallier et al. (2003) lacked sensitivity and that further testing might uncover effects of the early exposure to Korean. With Valerie Ventureyra, we ran a series of behavioural experiments to test more thoroughly the remnants of Korean in a larger group of twenty adoptees. In brief, we found virtually no significant difference between the adoptees and native French speakers. For example, the adoptees did not perceive the differences between Korean plain, tense and aspirated stop consonants better than French participants (Ventureyra et al. 2005). The only difference between the adoptees and native French speakers came about in an experiment assessing

3. It would be desirable to know what happens when someone switches to a new language at an age above 10. Studies of language attrition in adults seem to indicate that they show much less attrition than children. Thus, it is possible that plots of language attrition as a function of age show a non-linearity around puberty. the recognition of the Korean number series: while the adoptees gave the highest scores to Korean recordings (but did not recognise them formally), the control participants who had never been exposed to Korean gave the highest scores to Thai and Chinese (Ventureyra \& Pallier 2004). As these were the only tone languages included in the recordings, this may reflect an implicit knowledge of adoptees that Korean is not a tone language.

One important question is whether the adoptees could relearn their native language faster or better than people who have never been exposed to Korean. If the adoptees showed such an advantage, this would provide evidence for remnant traces of early exposure to Korean. From an anecdotal point of view, the adoptees who visited Korea for short stays (from a few days to a few months) did not miraculously recover the ability to speak or comprehend the language, and nor did the few who took Korean courses.

Some researchers have reported benefits of exposure to a language in infancy or childhood when relearning it (Au, Knightly, Jun \& Oh 2002; Oh, Jun, Knightly \& Au 2003; Tees \& Werker 1984). For example, Oh et al. (2003) evaluated the perception and production of Korean consonants by three groups enrolled in Korean language classes: one group had spoken Korean regularly for a few years during childhood, another group had heard Korean regularly during childhood but had spoken it minimally, and a last group consisted of novice learners. The first two groups performed better than the novice learners, demonstrating long-term benefits of early childhood experience with Korean. In these studies, however, the participants were not completely severed from the language of interest. In the study by Oh et al. (2003), for example, the participants had been continuously exposed to Korean for four hours a week on average. Therefore, their situation was quite different from that of adoptees who had not been exposed at all to Korean since adoption. Whether or not the adoptees would relearn their Ll faster than novice learners remains an open question. ${ }^{4}$

Let us now consider the L2 learned by the adoptees. Data from brain activations comparing the activations elicited by French and foreign languages show similar patterns in the adoptees and the control group of native French speakers (Pallier et al. 2003). Thus, the processing of French recruits the same brain areas

4. A phonetic training experiment, described in Ventureyra's thesis, was set up. Unfortunately, most participants did not complete it, probably because the starting level of difficulty was too high. This study is therefore not conclusive. Ideally, the participants in a retraining experiment should be adoptees who enrolled in Korean language classes and have a high degree of motivation. At the 2nd International Conference on First Language Attrition held in 2005 in Amsterdam, Kenneth Hyltenstam mentioned results obtained by Hyeon-Sook Park at the University of Stockholm suggesting that after a few months of courses, Korean adoptees perceived Korean consonants better than novice learners. 
in both groups. Note however that this is a comparison between groups and that there is non-negligible interindividual variability. Therefore it cannot be determined if the brain areas used by the adoptees to process French are precisely the same that they used for processing Korean in their childhood (Kim, Relkin, Lee \& Hirsch 1997). Only a longitudinal study, where children could be scanned before and after adoption, would settle this question.

A most important question regards the level of proficiency attained in French by the adoptees. Pallier et al. (2003) did not provide any formal assessment of this. We remarked informally that the adoptees spoke French fluently without any noticeable accent. Yet, more stringent tests might reveal limitations in their control of French (Cutler, Mehler, Norris \& Segui 1989). Two further experiments are relevant. The first assessed the sensitivity to phonotactic rules that differ between French and Korean. Korean speakers report hearing a vowel within certain types of illegal consonant clusters, a phenomenon known as vowel epenthesis (Dupoux, Kakehi, Hirose, Pallier \& Mehler 1999). Korean participants who have been speaking French for a few years still experience this illusion. When we tested adoptees, however, we found that they perceived consonant clusters in the same way as native French speakers do. Their speech perception system has become tuned to French phonotactic properties.

The second experiment dealt with lexical gender, a feature which is particularly difficult to acquire for native speakers of Korean who learn French as an L2. The participants listened to French sentences, some of which contained either gender agreement mistakes or semantic anomalies. The participants were instructed to press a button as soon as they detected any type of anomaly in a sentence, allowing measurement of both error rates and reaction times. Beside a group of adoptees and a group of native French participants, the experiment also included a third group of native Koreans, speakers of French as an L2 who had been living in France for a few years. The results showed that, as expected, this last group had great difficulties in detecting gender agreement mistakes. By contrast, the adoptees' performance was similar to that of native speakers of French. This was the case even for the participants who arrived in France when they were around 8 to 10 years of age (and in none of the experiments did the age of adoption correlate with the participants' scores.)

These experiments demonstrate that the adoptees had mastered the phonotactics of French and its lexical gender system. Of course, one cannot exclude the possibility that more demanding tasks might eventually reveal deficiencies in the adoptees' control of French.

The set of data obtained in these series of experiments, as well as Mayberry et al's results on post-lingually deaf who learned ASL after 9 years of age, argue against irreversible modifications occurring in the first ten years of life, either be- cause of maturational constraints or as a by-product of learning the L1. Provided one is exposed to a language in the first years of life, the language systems probably remain highly plastic until at least 10 years of age.

If so, one may ask why an L2 acquired in the first 10 years of life is not necessarily perfectly mastered? Our experiments on adoptees were inspired by the interference hypothesis according to which $\mathrm{L} 2$ acquisition is hampered by L1. To definitely prove this hypothesis, however, it would be necessary to compare the adoptees with immigrants having a similar background, and who have learned L2 while continuing to use their $\mathrm{L}$ l. If the interference account is correct, then the adoptees should have a better proficiency in the L2 than the immigrants. We hope that such a study can be conducted in the future.

Finally, it is interesting to know what happens when someone switches to a new language at an age above 10. In fact, studies of language attrition suggest that adults show much less attrition than children (Ammerlaan 1996; Pelc 2001 reviewed by Köpke \& Schmid 2004). Thus, language attrition, contrary to L2 ac quisition, may show a discontinuity around puberty.

\section{References}

Ammerlaan, T. (1996). "You get a bit wobbly..." - Exploring bilingual lexical retrieval processes in the context of first language attrition. Unpublished Doctoral Dissertation, Nijmegen: Katholieke Universiteit Nijmegen.

$\mathrm{Au}$, T. K., Knightly, L. M., Jun, S.-A. \& Oh, J. S. (2002). “Overhearing a language during childhood". Psychological Science, 13 (3), 238-243.

Best, C. (1995). “A direct realist view of cross-language speech perception". In W. Strange (Ed.), Speech Perception and Linguistic Experience: Theoretical and methodological issues (pp. 171-204). Baltimore, MD: York Press.

Bever, T. (1981). "Normal acquisition processes explain the critical period for language learning". In K. Diller (Ed.), Individual Differences in Language Learning Aptitude (pp. 176-198). Rowley, MA: Newbury House.

Birdsong, D. (Ed.) (1999a). Second Language Acquisition and the Critical Period Hypothesis. Mahwah, NJ: Lawrence Erlbaum Associates.

Birdsong, D. (1999b). "Whys and why nots of the critical period hypothesis for second language acquisition”. In D. Birdsong (Ed.), Second Language Acquisition and the Critical Period Hypothesis (pp. 1-22). Mahwah, NJ: Lawrence Erlbaum Associates.

Birdsong, D. \& Molis, M. (2001). "On the evidence for maturational constraints in secondlanguage acquisition". Journal of Memory and Language, 44, 235-249.

Bongaerts, T. (1999). "Ultimate attainment in second language pronunciation: The case of very advanced late second language learners". In D. Birdsong (Ed.), Second Language Acquisition and the Critical Period Hypothesis (pp. 133-159). Mahwah, NJ: Lawrence Erlbaum Associates. 
Cutler, A., Mehler, J., Norris, D. \& Segui, J. (1989). "Limits on bilingualism”. Nature, 340, $229-$ 230.

Dechert, H. W. (1995). "Some critical remarks concerning Penfield's theory of second language acquisition". In D. Singleton \& Z. Lengyel (Eds.), The Age Factor in Second Language Acquisition (pp. 67-94). Clevedon: Multilingual Matters.

Doupe, A. J. \& Kuhl, P. K. (1999). "Birdsong and human speech: Common themes and mechanisms". Annual Review of Neuroscience, 22, 567-631.

Dupoux, E., Kakehi, K., Hirose, Y., Pallier, C. \& Mehler, J. (1999). "Epenthetic vowels in Japanese: A perceptual illusion?" Journal of Experimental Psychology: Human Perception and Performance, 25, 1568-1578.

Flege, J. E. (1999). Age of learning and L2 speech. In D. Birdsong (Ed.), Second Language Acquisition and the Critical Period Hypothesis (pp. 101-131). Mahwah, NJ: Erlbaum.

Flege, J. E., Munro, M. J. \& MacKay, I. R. A. (1995). "Factors affecting strength of perceived foreign accent in a second language". Journal of the Acoustical Society of America, 97, 3125 3134.

Hakuta, K., Bialystok, E. \& Wiley, E. (2003). "Critical evidence: A test of the critical-period hypothesis for second language acquisition". Psychological Science, 14, 31-38.

Harley, B. \& Wang, W. (1997). "The critical period hypothesis: Where are we now?". In A. M. B. de Groot \& J. F. Kroll (Eds.), Tutorials in Bilingualism: Psycholinguistic perspectives (pp. 19-51). Mahwah, NJ: Lawrence Erlbaum Associates.

Hyltenstam, K. \& Abrahamsson, N. (2003). "Maturational constraints in SLA". In C. J. Doughty \& M.H. Long (Eds.), Handbook of Second Language Acquisition (pp. 539-588). Oxford: Blackwell.

Itard, J. (1964). "Mémoire et rapport sur Victor de l'Aveyron". In L. Malson (Ed.), Les enfants sauvages: Mythes et réalité (pp. 119-246). Paris: Union Général d’éditions 10/18.

Kim, K. H. S., Relkin, N. R., Lee, K.-M. \& Hirsch, J. (1997). “Distinct cortical areas associated with native and second languages". Nature, 388, 171-174.

Klima, E. \& Bellugi, U. (1979). The Signs of Language. Cambridge, MA: Harvard University Press.

Köpke, B. \& Schmid, M. S. (2004). "Language attrition: The next phase". In M. S. Schmid, B. Köpke, M. Keijzer \& L. Weilemar (Eds.), First Language Attrition: Interdisciplinary perspectives on methodological issues (pp. 1-46). Amsterdam: John Benjamins.

Lee, D. S., Lee, J. S., Oh, S. H., Kim, S.-K., Kim, J.-W., Chung, J.-K., Lee, M. C. \& Kim, C. S. (2001). "Cross-modal plasticity and cochlear implants". Nature, 409, 149-150.

Lenneberg, E. H. (1967). Biological Foundations of Language. New York, NY: Wiley.

Long, M. (1990). "Maturational constraints on language development". Studies in Second Language Acquisition, 12, 251-285.

Maury, F. (1995). Les mécanismes intrapsychiques de ladoption internationale et interraciale. $L$ 'adoption des enfants coréens en France. Unpublished Doctoral Dissertation, Paris: Université de Paris VIII.

Maury, F. (1999). L' adoption interraciale. Paris: L'Harmattan.

Mayberry, R. I. \& Eichen, E. B. (1991). “The long-lasting advantage of learning sign language in childhood: Another look at the critical period for language acquisition". Journal of Memory and Language, 30, 486-512.
McConkey Robbins, A, Burton Koch, D. Osberger, M. I., Zimmerman-Philips, S. \& KishonRabin, L. (2004). "Effect of age at cochlear implantation on auditory skill development in infants and toddlers". Archives of Otolaryngology Head \& Neck Surgery, 130, 570-574.

Newport, E. L. (1990). "Maturational constraints on language learning". Cognitive Science, 14, $11-28$.

Newport, E. L., Bavelier, D. \& Neville, H. J. (2001). "Critical thinking about critical periods: Perspectives on a critical period for language acquisition". In E. Dupoux (Ed.), Language, Brain and Cognitive Development (pp. 481-502). Cambridge, MA: MIT Press.

Oh, J. S., Jun, S.-A., Knightly, L. M. \& Au, T. K.-f. (2003). "Holding on to childhood language memory". Cognition, 86, B53-B64.

Oyama, S. (1976). "A sensitive period for the acquisition of a nonnative phonological system". Journal of Psycholinguistic Research, 5, 261-283.

Pallier, C., Bosch, L. \& Sebastian-Gallés, N. (1997). "A limit on behavioral plasticity in speech perception". Cognition, 64, B9-B17.

Pallier, C., Dehaene, S., Poline, J.-B., LeBihan, D., Argenti, A.-M., Dupoux, E. \& Mehler, J. (2003). "Brain imaging of language plasticity in adopted adults: Can a second language replace the first?" Cerebral Cortex, 13, 155-161.

Pelc, L. (2001). L1 Lexical, Morphological and Morphosyntactic Attrition in Greek-English Bilinguals. Unpublished Doctoral Dissertation, New York, NY: City University of New York.

Penfield, W. (1965). "Conditioning the uncommitted cortex for language learning". Brain, 88, 787-798.

Penfield, W. \& Roberts, L. (1959). Speech and Brain Mechanisms. Princeton, NJ: Princeton University Press.

Pinker, S. (1994). The Language Instinct. New York, NY: W. Morrow and Co.

Sangrigoli, S., Pallier, C., Argenti, A.-M., Ventureyra, V. \& de Schonen, S. (2005). "Reversibility of the other-race effect in face recognition during childhood". Psychological Science, 16, $440-444$.

Singleton, D. (1995). "A critical look at the critical period hypothesis in second language acquisition research". In D. Singleton \& Z. Lengyel (Eds.), The Age Factor in Second Language Acquisition: A critical look at the critical period hypothesis (pp. 1-29). Clevedon: Multilingual Matters.

Singleton, D. \& Lengyel, Z. (Eds.) (1995). The Age Factor in Second Language Acquisition: A critical look at the critical period hypothesis. Clevedon: Multilingual Matters.

Strange, W. (Ed.) (1995). Speech Perception and Linguistic Experience: Theoretical and methodological issues. Baltimore, MD: York Press.

Tees, R C \& Werker, J. F. (1984). "Perceptual flexibility: Maintenance or recovery of the ability to discriminate non-native speech sounds". Canadian Journal of Psychology, 38, 579-590.

Tomblin, J., Barker, B., Spencer, L., Zhang, X. \& Gantz, B. (2005). "The effect of age at cochlear implants initial stimulation on expressive language growth in infants and toddlers". Journal of Speech, Language and Hearing Research, 48, 853-867.

Ventureyra, V. (2005). A la recherche de la langue perdue: Étude psycholinguistique del' attrition de la première langue chez des Coréens adoptés en France. Unpublished Doctoral Dissertation, Paris: Ecole des Hautes Etudes en Sciences Sociales. 
Ventureyra, V. \& Pallier, C. (2004). "In search of the lost language: The case of adopted Koreans in France". In M. S. Schmid, B. Köpke, M. Keijzer \& L. Weilemar (Eds.), First Language Attrition: Interdisciplinary perspectives on methodological issues (pp. 207-221). Amsterdam: John Benjamins.

Ventureyra, V., Pallier, C. \& Yoo, H.-Y. (2004). "The loss of first language phonetic perception in adopted Koreans". Journal of Neurolinguistics, 17, 79-91.

Weber-Fox, C. M. \& Neville, H. J. (1996), "Maturational constraints on functional specializations for language processing: ERP and behavioral evidence in bilingual speakers". Journal of Cognitive Neuroscience, 8, 231-256.

\section{A hidden language}

Recovery of a 'lost' language is triggered by hypnosis

Rosalie Footnick

Unité de Neuroimagerie Cognitive (CEA INSERM U562), Orsay, France

Our case study confirms two previous studies demonstrating that a 'lost' language can be recovered by hypnosis. These results point to the existence of another type of attrition. Here a distinction is made between this type of attrition of a 'hidden language' ( $\mathrm{HL}$ ), that is, one that has not been forgotten but rather has become inaccessible to the speaker, and the traditionally studied attrition of a 'forgotten language' (FL). A conflict hypothesis is proposed to explain HL attrition. An attempt is made to show how these two types of attrition could be distinguished and to explain why brain imagery analyses are important for this distinction.

Keywords: hypnosis; neuroimaging; language forgetting; accessibility; Ewe

\section{Introduction}

Investigations into language attrition can encounter at least three different types of language loss, and for each type, loss can be either partial or total. The first type of language loss results in a language system that can be called Type AL (abnormal language), because the speech produced is clearly abnormal. This type is pathological in origin as a direct result of physiological damage to the brain or other parts of the speech system. This type of language loss is very well documented by the extensive literature on aphasia, agnosia, agrammatism, etc. (e.g. Caplan 1992; de Bleser 2003). A second type of attrited language system, non-pathological in nature, can be designated as Type FL for a forgotten language. This type occurs when a speaker has acquired a native language ${ }^{1}$ which, either through lack of use together with the use of another one, or through interference when two or more

1. Attrition can also affect a second or foreign language, but here we are concerned with $\mathrm{L}$ attrition. 